\title{
FHL2 suppresses growth and differentiation of the colon cancer cell line HT-29
}

\author{
THOMAS AMANN $^{1 *}$, YVONNE EGLE $^{1 *}$, ANJA-KATRIN BOSSERHOFF $^{2}$ and CLAUS HELLERBRAND ${ }^{1}$ \\ ${ }^{1}$ Department of Internal Medicine I, University Hospital Regensburg; \\ ${ }^{2}$ Institute of Pathology, University of Regensburg, Regensburg, Germany
}

Received December 10, 2009; Accepted January 12, 2010

DOI: 10.3892/or_00000810

\begin{abstract}
Four and a half LIM domain protein 2 (FHL2) can interact with many proteins and regulates different cellular processes, including proliferation and differentiation. FHL2 expression is often deregulated in cancer and may act as both tumor-promoter or tumor-suppressor depending on the type of cancer. Thus, a previous study found that increased FHL2 expression in colon cancer and suppression of FHL2 in a colon cancer cell line with endogenously high FHL2 expression inhibited tumor growth. We applied the opposite strategy, an FHL2 expression plasmid was stably transfected into HT-29 cells, a colon carcinoma cell line which exhibits very low basal levels of FHL2. Stable expression of FHL2 in HT-29 cells induced a $\mathrm{G} 2 / \mathrm{M}$ arrest and inhibited anchorage-dependent and -independent growth in vitro. Further, FHL2 expressing HT-29 cell clones revealed significantly higher expression of the differentiation marker E-cadherin but reduced activity of the transcription factor NF- $\mathrm{B}$, which is known to promote colon cancer progression. These findings further underscore the complex role of FHL2 in tumorigenicity, with even different effects on cellular functions of cancer cell lines derived from the same type of tumor and distinctly suggest caution regarding therapeutic strategies targeting FHL2 to treat (colon) cancer.
\end{abstract}

\section{Introduction}

Colorectal cancer (CRC) is one of the most frequent human tumors and the third leading cause of cancer death (1). The prognosis of CRC, especially advanced cancer, has not substantially improved although the molecular mechanisms of CRC have become better understood in the past two decades (2).

Correspondence to: Dr Claus Hellerbrand, Department of Internal Medicine I, University of Regensburg, D-93042 Regensburg, Germany

E-mail: claus.hellerbrand@klinik.uni-regensburg.de

*Contributed equally

Key words: colorectal cancer, HT-29, FHL2, NF-кB, E-cadherin, differentiation, proliferation
Four and a half LIM protein 2 (FHL2), also known as down-regulated in rhabdomyosarcoma LIM (DRAL) domain protein, is a member of a small family of five proteins with four and a half LIM domains (3). The abbreviation LIM represents the names of three transcription factors (Lin-11,

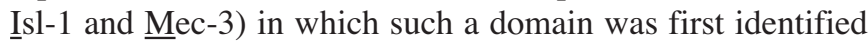
(4). The LIM domains are double zinc finger motifs that play multiple roles in protein-protein interaction (5). FHL2 can interact with $>50$ different proteins with diverse functions such as receptors, enzymes, transcription factors, cofactors or splicing factors (6). Thus, FHL2 is involved in the regulation of various cellular processes including proliferation, differentiation, migration and contraction (7-10). FHL2 can function as repressor or activator of transcriptional activity, and noteworthy, depending on the cell type even the expression of the same gene or distinguished cellular functions, respectively, may be regulated in different ways. Thus, FHL2 promotes expression of $\alpha$-smooth-muscle actin ( $\alpha$-SMA) and contractility in myofibroblasts of the skin (9), but inhibits $\alpha$-SMA expression and contractility of cardiac muscle cells (11).

Also the role of FHL2 in tumorigenesis is complex, since it may act as an oncoprotein or as a tumor suppressor depending on the type of cancer $(6,12)$. FHL2 was first identified in human rhabdomyosarcoma cells as a downregulated gene indicating a role as tumor suppressor (13) and reduced FHL2 expression was also found in prostate and hepatocellular cancer $(14,15)$. In contrast, increased expression of FHL2 was detected in breast, lung, and ovarian cancer, as well as glioblastoma and melanoma (16-20). Further, Wang et al found higher FHL2 expression in colon cancerous tissues compared to normal tissues, and the same authors described, that suppression of FHL2 in a colon cancer cell line with endogenously high FHL2 expression inhibited tumor growth (21).

Here, we applied the opposite strategy, we induced FHL2 expression in the colon carcinoma cell line HT-29, which exhibits very low basal levels of FHL2. Noteworthy, it was observed that stable expression of FHL2 induced the expression of the differentiation marker E-cadherin and inhibited the growth of this cell line. Herewith, our study revealed for the first time that FHL2 may affect the same biological mechanisms, e.g. growth and differentiation, in opposite ways even within tumorous cells derived from the same type of cancer. 


\section{Materials and methods}

Cells and cell culture. The colorectal carcinoma cell line HT-29 (ATCC HTB-38) was cultured as described (22). Briefly, cells were maintained in DMEM (PAA, Karlsruhe, Germany) supplemented with penicillin $(400 \mathrm{U} / \mathrm{ml})$, streptomycin $(50 \mu \mathrm{g} / \mathrm{ml})$, L-glutamine $(300 \mu \mathrm{g} / \mathrm{ml})$ and $10 \%$ fetal calf serum (FCS; Sigma, Deisenhofen, Germany) and passaged at a 1:5 ratio every three days.

Stable transfection of HT-29 cells with a FHL2 expression plasmid. FHL2 expressing cell clones were established by stable transfection of HT-29 cells with a FHL2 expression plasmid containing the selectable marker for neomycin resistance, kindly provided by Professor Roland Schüle (Center for Clinical Research, University of Freiburg, Germany) (9). Transfections were performed using lipofectamine 2000 (Invitrogen, Carlsbad, USA). Controls (mock) received the empty pcDNA3 plasmid. One day after transfection, cells were placed in selection medium containing $50 \mu \mathrm{g} / \mathrm{ml} \mathrm{G} 418$ (Sigma). After 25 days of selection, individual G418-resistant colonies were subcloned.

Expression analysis. Isolation of total cellular RNA from cultured cells and reverse transcription were performed as described (23). Quantitative real-time PCR was performed with specific sets of primers applying LightCycler technology (Roche Diagnostics, Mannheim, Germany) as described (23). The sequence of the primers was as follows: $\beta$-actin forward: 5'-CTA CGT CGC CCT GGA CTT CGA GC; 3 -actin reverse: 5'-GAT GGA GCC GCC GAT CCA CAC GG; FHL2 forward: 5'-GAA ACT CAC TGG TGG ACA AGC; FHL2 reverse: 5'-GTG GCA GAT GAA GCA GGT CT; E-cadherin forward: 5'-TAA CCG ATC AGA ATG AC; E-cadherin reverse: 5'-TTT GTC AGG GAG CTC AGG AT.

Protein analysis. Protein extraction and Western blotting were performed as described $(23,24)$. For FHL2 detection the monoclonal FHL2 antibody (Hycult Biotech, Uden, The Netherlands) was used at a dilution of 1:200.

Cell cycle analysis. Nuclear DNA content was measured by using propidium iodide (PI) staining and fluorescenceactivated cell sorting (FACS) analysis as described (25). Briefly, $10^{6}$ cells were fixed in ice-cold methanol (70\%) for $1 \mathrm{~h}$ on ice, washed twice with PBS and resuspended in PBS. Fixed cells were treated with RNase $(0.01 \mathrm{mg} / \mathrm{ml}$; Roche Molecular Biochemicals) for $30 \mathrm{~min}$ at $37^{\circ} \mathrm{C}$, stained with $50 \mu \mathrm{g} / \mathrm{ml}$ propidium iodide (PI; Sigma) and kept in the dark on ice for $30 \mathrm{~min}$ before analysis. Cell cycle analysis was carried out using an EPICS XL-MCL flow cytometer (Beckman Coulter, Krefeld, Germany). Data were analyzed with the Multicycle software (Becton-Dickinson, Heidelberg, Germany).

Quantification of phoshorylated $N F-\kappa B$ p65. NF- $\kappa$ B was quantified in nuclear extracts with the ELISA-based kit TransAm from Active Motif (Rixensart, Belgium) according to the manufacturer's instructions, as described (22).
A

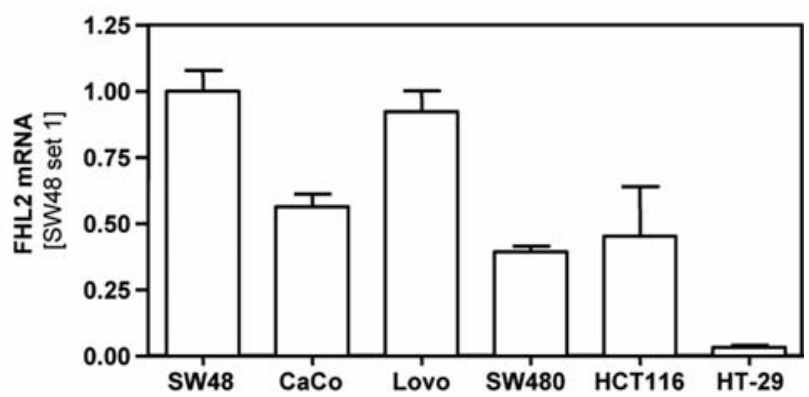

B

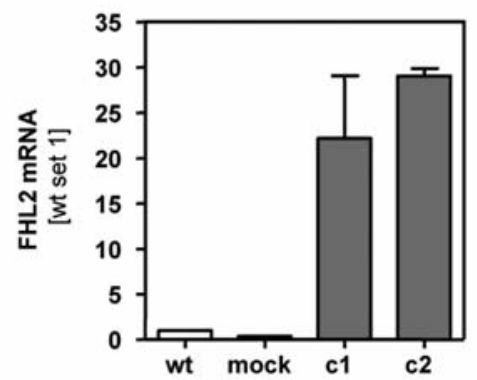

C

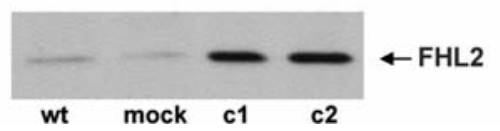

Figure 1. FHL2 expression in HT-29 cells. (A) Analysis of FHL2 expression in HT-29 and five other colon cancer cell lines (SW48, CaCo, Lovo, SW480 and HCT116) by quantitative PCR. Analysis of (B) FHL2 mRNA and (C) protein expression in HT-29 cell clones stably transfected with a FHL2 expression plasmid (c1 and c2), mock-transfected controls (mock) and nontransfected cells (wt) as assessed by quantitative RT-PCR and Western blotting.

Proliferation and colony formation assays. Cell proliferation was measured using the XTT assay (Roche Diagnostics) as described (23).

To analyze anchorage-independent growth cells were seeded into 6-well plates in DMEM, 0.36\% agar (Sigma), supplemented with $10 \%$ FCS on top of a $0.72 \%$ agar bed in similar medium. The cultures were incubated for 14 days and the colonies were quantified and photographed (26).

Statistical analysis. Results are expressed as mean \pm standard error (range) or percent. Comparison between groups was made using the Student's unpaired t-test. A P-value $<0.05$ was considered statistically significant. All calculations were performed by using the GraphPad Prism Software (GraphPad Software, Inc., San Diego, USA).

\section{Results}

Re-expression of FHL2 in HT-29 cells. Initially, we determined FHL2 expression in different colon cancer cell lines. Quantitative PCR analysis revealed significant differences between individual cell lines, with the lowest FHL2 expression levels in HT-29 cells (Fig. 1A).

To gain insight into the role of reduced FHL2 expression in HT-29 cells, FHL2 was re-induced by stable transfection with a FHL2 expression vector containing the full-length 
A

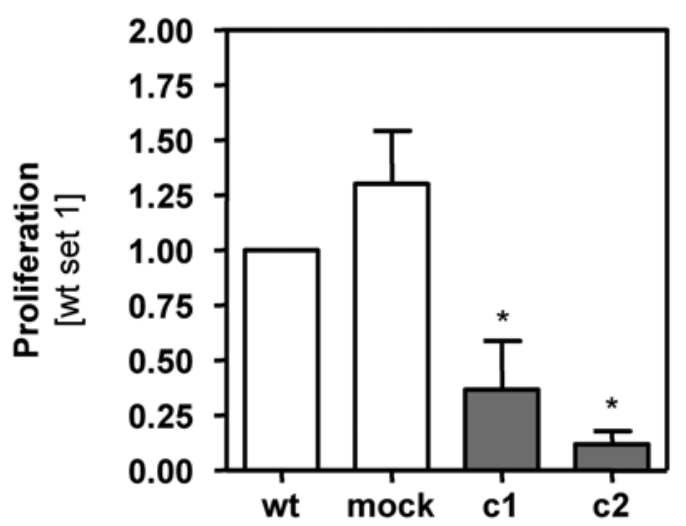

B
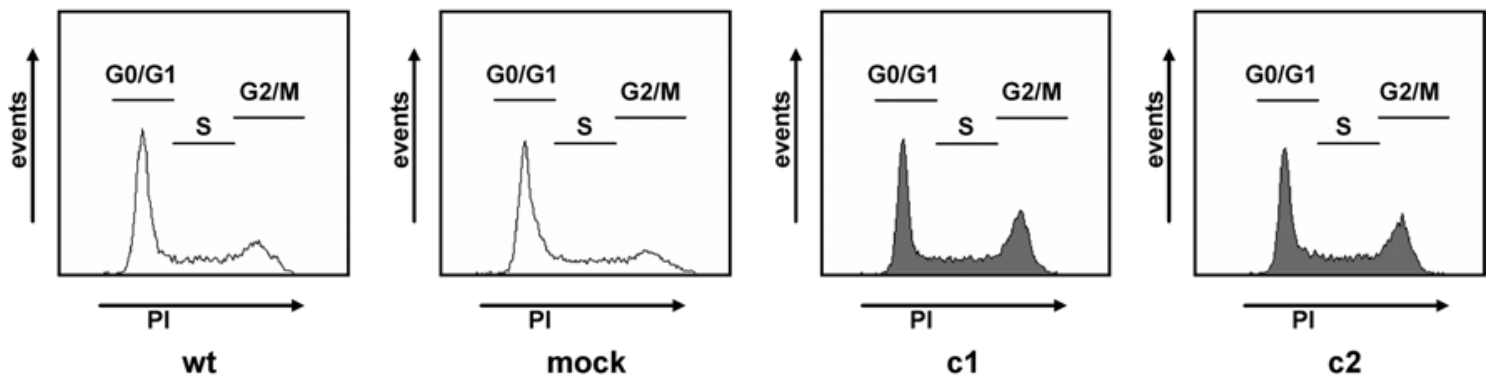

C

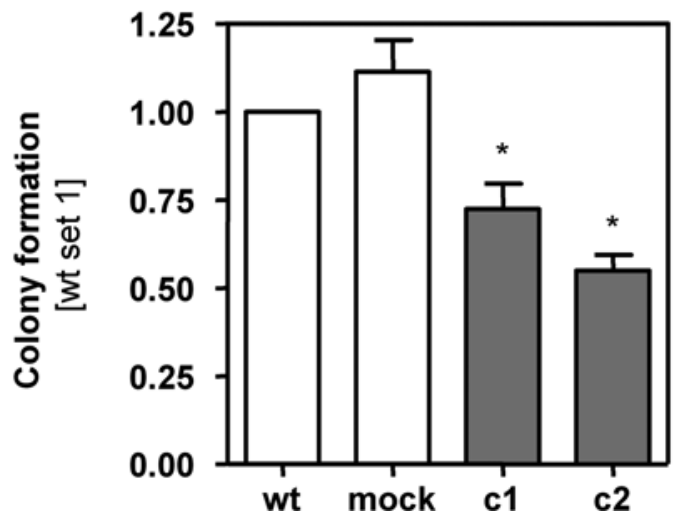

Figure 2. Growth of FHL2 expressing HT-29 cell clones. (A) Proliferation of HT-29 cell clones stably expressing FHL2 (c1 and c2), mock-transfected cells (mock) and non-transfected (wt) controls. (B) Propidium iodide (PI) staining and FACS analysis were applied to investigate cell cycle (GO/G1-, S- and G2/M phase). (C) Attachment-independent growth analyzed by soft agar colony formation assays. ( ${ }^{*} \mathrm{P}<0.05$ compared to wt and mock).

FHL2 cDNA under the control of the cytomegalovirus promotor (clone 1 and 2). The vector without an insert was used as a control (mock). Quantitative RT-PCR analysis revealed a strong induction of FHL2 mRNA expression in the cell clones, whereas barely no (change of) FHL2 expression was seen in mock-transfected cell clones (Fig. 1B). Upregulation of FHL2 expression in the cell clones was confirmed on protein level by Western blotting (Fig. 1C). Equal protein loading was controlled by Ponceau-S staining (data not shown).

Effect of FHL2 re-expression on growth of HT-29 cells. To further characterize the role of FHL2 in HT-29 cells, we performed functional in vitro assays. Proliferation was significantly impaired in FHL2 expressing cell clones in comparison to mock-transfected cells and the parental cell line (Fig. 2A).
Cell cycle analysis revealed that the fraction of FHL2 cell clones that retained in the $\mathrm{G} 2 / \mathrm{M}$ phase (clone 1 : $32.0 \pm 2.7 \%$ and clone $2: 30.7 \pm 0.3 \%$ ) was significantly higher than the fraction found within mock-transfected control cells

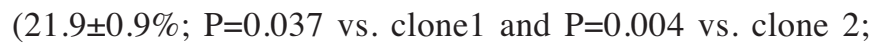
Fig. 2B).

To determine whether FHL2 modulates also anchorageindependent growth, we analyzed the colony formation of cells in standard soft agar assays. HT-29 cells stably expressing FHL2 showed diminished growth while mock or nontransfected cells formed numerous colonies in soft agar (Fig. 2C).

Effect of FHL2 re-expression on morphology and differentiation of HT-29 cells. To further characterize the effect of FHL2 HT-29 cells, we examined the morphological features 
A

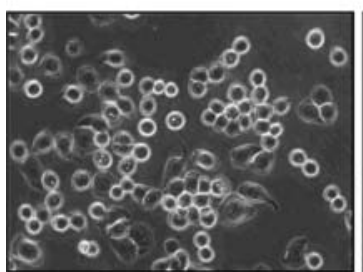

wt

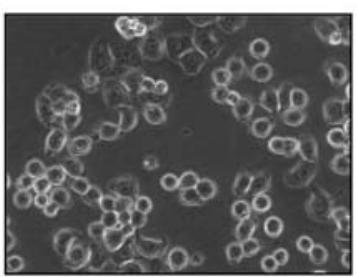

mock

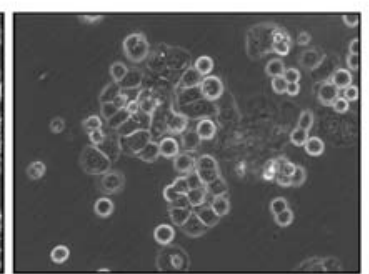

c1

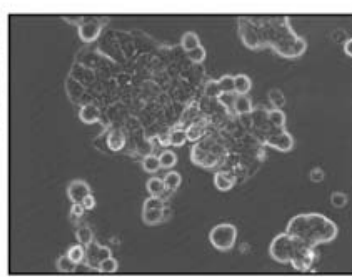

c2

B

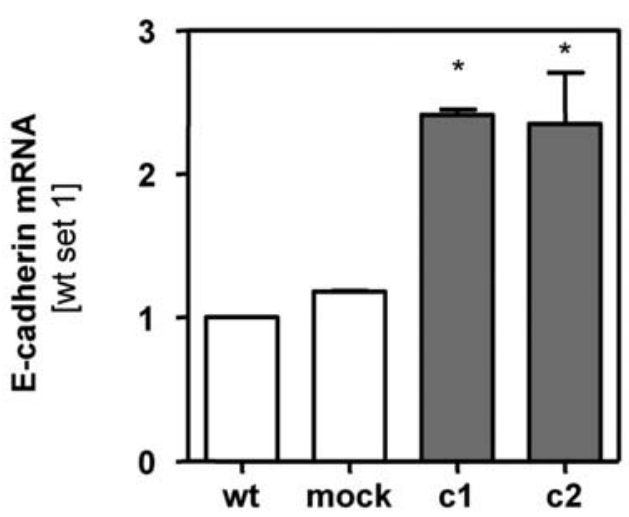

C

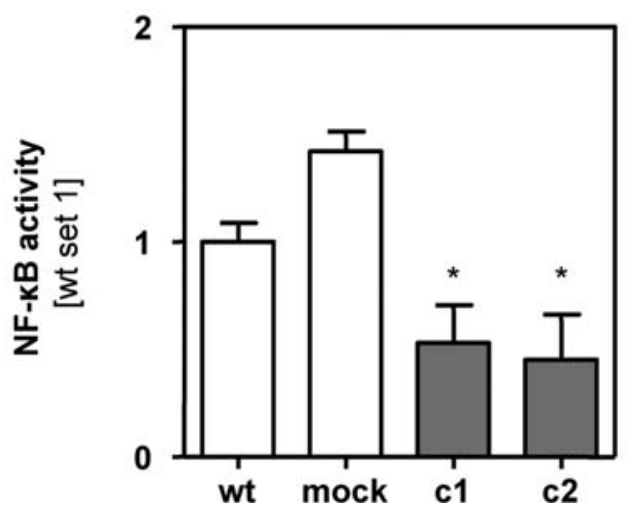

Figure 3. Morphology, E-cadherin expression and NF-кB activity in FHL2 expressing HT-29 cell clones. (A) Phase contrast images of HT-29 cell clones stably expressing FHL2 (c1 and c2), mock-transfected cells (mock) and non-transfected (wt) controls grown in standard medium on plastic dishes. (B) E-cadherin mRNA expression analyzed by quantitative PCR. (C) NF-кB activity in nuclear extracts. ${ }^{*} \mathrm{P}<0.05$ compared to wt and mock.

of FHL2 expressing cell clones in comparison to control cells under phase contrast. While mock-transfected and parental HT-29 cells grow as homogeneous cell layers with defined intercellular junctions, FHL2 expressing clones revealed a multicellular spheroid configuration leaving large cell-free spaces (Fig. 3A).

In many cell types cell-cell adhesion is mediated by cadherins and it has been shown before, that induced Ecadherin expression, as observed during enterocyte differentiation, promotes aggregation of HT-29 cells (27). Notably, FHL2 expressing cell clones revealed significantly increased E-cadherin expression in comparison to control cells (Fig. 3B), suggesting that FHL2 induced E-cadherin stimulated differentiation and cell-cell adhesion in HT-29 cells.

Further, loss of E-cadherin expression correlates with the activation of the transcription factor $\mathrm{NF}-\kappa \mathrm{B}$, known to play a critical role in the progression of colon cancer $(28,29)$.
Interestingly, NF- $\mathrm{\kappa B}$ activity in nuclear extracts of FHL2 expressing HT-29 cell clones was significantly lower than in control cells (Fig. 3C).

\section{Discussion}

In the present study, we analyzed the effects of FHL2 expression in colon carcinoma HT-29 cells. FHL2 induced a G2/M arrest, and inhibited anchorage-dependent and independent growth. Further, we observed elevated Ecadherin expression in cell clones stably expressing FHL2. E-cadherin is induced during enterocyte differentiation while a loss of E-cadherin is found in poorly differentiated carcinomas of the colon (30). We and others have shown an inverse functional correlation between E-cadherin expression and NF- $\mathrm{KB}$ activity $(28,29,31)$ and accordingly, NF- $\mathrm{\kappa B}$ activity was significantly reduced in FHL2 expressing HT-29 cell 
clones. FHL2 has been shown to attenuate NF-кB activity (32) and Ding et al found that FHL2 also inhibited anchoragedependent and -independent growth of hepatocellular carcinoma cells through a TGF-ß-like signaling pathway (15).

In contrast to our results Wang et al found that FHL2 inhibition with siRNA induced proliferation and differentiation of the colon cancer cell line Lovo (21) and the same authors described, that suppression of FHL2 decreased NF- $\mathrm{KB}$ activity in the colon cancer cell line DLD1 (33). In contrast to HT29 cells, Lovo and DLD1 cells are poorly differentiated colon cancer cell lines and do express high levels of FHL2 (21). Still, although significantly lower, FHL2 expression is detectable in HT29 cells indicating that FHL2 depletion in these cells is not a result of the absence of the gene. Further, one may speculate whether mutations in the FHL2 gene alter the function of the protein in HT-29 cells or the other colon cancer cell lines, respectively. However, we sequenced the four coding regions of HT-29 as well as HCT116, CaCo, LoVo, SW48, and SW480 cells and could not detect mutations (data not shown).

Thus, currently we can only speculate on the molecular mechanisms how FHL2 is differentially regulated and even exhibits opposite effects, respectively, in HT-29 cells as compared to other colon cancer cell lines. Previous studies have shown that FHL2 may act as both an oncoprotein or a tumor suppressor depending on the type of cancer (13-20). Here, we newly demonstrate that FHL2 even differently affects gene expression and cellular functions, respectively, of cancer cell lines derived from the same type of cancer. These findings further underline the complex role of FHL2 in tumorigenesis and draw attention to the need for caution regarding therapeutic strategies targeting FHL2 to treat (colon) cancer.

\section{Acknowledgements}

We are indebted to Kornelia Elser for excellent technical assistance. This study was supported by grants from the German Research Association (DFG) to A.K.B. and the Medical Faculty of the University of Regensburg (ReForM) to A.K.B. and C.H.

\section{References}

1. Jemal A, Siegel R, Ward E, Hao Y, Xu J and Thun MJ: Cancer statistics 2009. CA Cancer J Clin 59: 225-249, 2009.

2. Li FY and Lai MD: Colorectal cancer, one entity or three. J Zhejiang Univ Sci B 10: 219-229, 2009.

3. Chan KK, Tsui SK, Lee SM, Luk SC, Liew CC, Fung KP, Waye MM and Lee CY: Molecular cloning and characterization of FHL2, a novel LIM domain protein preferentially expressed in human heart. Gene 210: 345-350, 1998.

4. Sanchez-Garcia I, Osada H, Forster A and Rabbitts TH: The cysteine-rich LIM domains inhibit DNA binding by the associated homeodomain in Isl-1. EMBO J 12: 4243-4250, 1993.

5. Bach I: The LIM domain: regulation by association. Mech Dev 91: 5-17, 2000

6. Johannessen M, Moller S, Hansen T, Moens U and Van Ghelue M: The multifunctional roles of the four-and-a-half-LIM only protein FHL2. Cell Mol Life Sci 63: 268-284, 2006.

7. Labalette C, Nouet Y, Sobczak-Thepot J, Armengol C, Levillayer F, Gendron MC, Renard CA, Regnault B, Chen J, Buendia MA and Wei Y: The LIM-only protein FHL2 regulates cyclin D1 expression and cell proliferation. J Biol Chem 283: 15201-15208, 2008.
8. Martin B, Schneider R, Janetzky S, Waibler Z, Pandur P, Kuhl M, Behrens J, von der Mark K, Starzinski-Powitz A and Wixler V: The LIM-only protein FHL2 interacts with beta-catenin and promotes differentiation of mouse myoblasts. J Cell Biol 159: $113-122,2002$.

9. Wixler V, Hirner S, Muller JM, Gullotti L, Will C, Kirfel J, Gunther T, Schneider H, Bosserhoff A, Schorle H, Park J, Schule R and Buettner R: Deficiency in the LIM-only protein Fhl2 impairs skin wound healing. J Cell Biol 177: 163-172, 2007.

10. Hayashi H, Nakagami H, Takami Y, Koriyama H, Mori M, Tamai K, Sun J, Nagao K, Morishita R and Kaneda Y: FHL-2 suppresses VEGF-induced phosphatidylinositol 3-kinase/Akt activation via interaction with sphingosine kinase-1. Arterioscler Thromb Vasc Biol 29: 909-914, 2009.

11. Philippar U, Schratt G, Dieterich C, Muller JM, Galgoczy P, Engel FB, Keating MT, Gertler F, Schule R, Vingron M and Nordheim A: The SRF target gene Fhl2 antagonizes RhoA/ MAL-dependent activation of SRF. Mol Cell 16: 867-880, 2004.

12. Kleiber K, Strebhardt K and Martin BT: The biological relevance of FHL2 in tumour cells and its role as a putative cancer target. Anticancer Res 27: 55-61, 2007.

13. Genini M, Schwalbe P, Scholl FA, Remppis A, Mattei MG and Schafer BW: Subtractive cloning and characterization of DRAL, a novel LIM-domain protein down-regulated in rhabdomyosarcoma. DNA Cell Biol 16: 433-442, 1997.

14. Kinoshita M, Nakagawa T, Shimizu A and Katsuoka Y: Differently regulated androgen receptor transcriptional complex in prostate cancer compared with normal prostate. Int J Urol 12: 390-397, 2005.

15. Ding L, Wang Z, Yan J, Yang X, Liu A, Qiu W, Zhu J, Han J, Zhang H, Lin J, Cheng L, Qin X, Niu C, Yuan B, Wang X, Zhu C, Zhou Y, Li J, Song H, Huang C and Ye Q: Human four-and-ahalf LIM family members suppress tumor cell growth through a TGF-beta-like signaling pathway. J Clin Invest 119: 349-361, 2009.

16. Chen D, Xu W, Bales E, Colmenares C, Conacci-Sorrell M, Ishii S, Stavnezer E, Campisi J, Fisher DE, Ben Ze'ev A and Medrano EE: SKI activates Wnt/beta-catenin signaling in human melanoma. Cancer Res 63: 6626-6634, 2003.

17. Gabriel B, Mildenberger S, Weisser CW, Metzger E, Gitsch G, Schule R and Muller JM: Focal adhesion kinase interacts with the transcriptional coactivator FHL2 and both are overexpressed in epithelial ovarian cancer. Anticancer Res 24: 921-927, 2004.

18. Gabriel B, Fischer DC, Orlowska-Volk M, Zur Hausen A, Schule R, Muller JM and Hasenburg A: Expression of the transcriptional coregulator FHL2 in human breast cancer: a clinicopathologic study. J Soc Gynecol Investig 13: 69-75, 2006.

19. Li M, Wang J, Ng SS, Chan CY, Chen AC, Xia HP, Yew DT, Wong BC, Chen Z, Kung HF and Lin MC: The four-and-a-halfLIM protein 2 (FHL2) is overexpressed in gliomas and associated with oncogenic activities. Glia 56: 1328-1338, 2008.

20. Tanahashi $\mathrm{H}$ and Tabira T: Alzheimer's disease-associated presenilin 2 interacts with DRAL, an LIM-Domain protein. Hum Mol Genet 9: 2281-2289, 2000.

21. Wang J, Yang Y, Xia HH, Gu Q, Lin MC, Jiang B, Peng Y, Li G, An X, Zhang Y, Zhuang Z, Zhang Z, Kung HF and Wong BC: Suppression of FHL2 expression induces cell differentiation and inhibits gastric and colon carcinogenesis. Gastroenterology 132: 1066-1076, 2007

22. Muhlbauer M, Allard B, Bosserhoff AK, Kiessling S, Herfarth H, Rogler G, Scholmerich J, Jobin C and Hellerbrand C: Differential effects of deoxycholic acid and taurodeoxycholic acid on NFKappa B signal transduction and IL-8 gene expression in colonic epithelial cells. Am J Physiol Gastrointest Liver Physiol 286: 1000-1008, 2004.

23. Hellerbrand C, Amann T, Schlegel J, Wild P, Bataille F, Spruss T, Hartmann A and Bosserhoff AK: The novel gene MIA2 acts as a tumour suppressor in hepatocellular carcinoma. Gut 57: 243-251, 2007.

24. Hellerbrand C, Muhlbauer M, Wallner S, Schuierer M, Behrmann I, Bataille F, Weiss T, Scholmerich J and Bosserhoff AK: Promoter-hypermethylation is causing functional relevant downregulation of methylthioadenosine phosphorylase (MTAP) expression in hepatocellular carcinoma. Carcinogenesis 27: 64-72, 2006.

25. Kiessling S, Muller-Newen G, Leeb SN, Hausmann M, Rath HC, Strater J, Spottl T, Schlottmann K, Grossmann J, Montero-Julian FA, Scholmerich J, Andus, T, Buschauer A, Heinrich PC and Rogler G: Functional expression of the interleukin-11 receptor alpha-chain and evidence of antiapoptotic effects in human colonic epithelial cells. J Biol Chem 279: 10304-10315, 2004. 
26. Maegdefrau U, Amann T, Winklmeier A, Braig S, Schubert T, Weiss TS, Schardt K, Warnecke C, Hellerbrand C and Bosserhoff AK: Bone morphogenetic protein 4 is induced in hepatocellular carcinoma by hypoxia and promotes tumour progression. J Pathol 218: 520-529, 2009.

27. Chartier NT, Laine M, Gout S, Pawlak G, Marie CA, Matos P Block MR and Jacquier-Sarlin MR: Laminin-5-integrin interaction signals through PI 3-kinase and Rac1b to promote assembly of adherens junctions in HT-29 cells. J Cell Sci 119: 31-46, 2006

28. Simiantonaki N, Kurzik-Dumke U, Karyofylli G, Jayasinghe C and Kirkpatrick CJ: Loss of E-cadherin in the vicinity of necrosis in colorectal carcinomas: association with NFkappaB expression. Int J Oncol 31: 269-275, 2007.

29. Kuphal S, Poser I, Jobin C, Hellerbrand C and Bosserhoff AK Loss of E-cadherin leads to upregulation of NFkappaB activity in malignant melanoma. Oncogene 23: 8509-8519, 2004.

30. Kanazawa T, Watanabe T, Kazama S, Tada T, Koketsu S and Nagawa H: Poorly differentiated adenocarcinoma and mucinous carcinoma of the colon and rectum show higher rates of loss of heterozygosity and loss of E-cadherin expression due to methylation of promoter region. Int J Cancer 102: 225-229, 2002 .
31. Kokura S, Yoshida N, Imamoto E, Ueda M, Ishikawa T, Uchiyama K, Kuchide M, Naito Y, Okanoue T and Yoshikawa T: Anoxia/reoxygenation down-regulates the expression of Ecadherin in human colon cancer cell lines. Cancer Lett 211: 79-87, 2004.

32. Bai S, Kitaura H, Zhao H, Chen J, Muller JM, Schule R, Darnay B, Novack DV, Ross FP and Teitelbaum SL: FHL2 inhibits the activated osteoclast in a TRAF6-dependent manner. J Clin Invest 115: 2742-2751, 2005

33. Qiao L, Wang Y, Pang R, Wang J, Dai Y, Ma J, Gu Q, Li Z, Zhang Y, Zou B, Lan HY and Wong BC: Oncogene functions of FHL2 are independent from NF-KappaBIalpha in gastrointestinal cancer. Pathol Oncol Res 15: 31-36, 2009. 